\title{
MARKETING LEADERSHIP: THE INDUSTRY 4.0 NEED OF NEXT GENERATION MARKETING
}

\author{
N. Sterev* \\ University of National and World Economy, Sofia, Bulgaria
}

\begin{abstract}
The evolution to Industry 4.0 the Bulgarian business needs to improve not just innovations and human resources, but to change their "software" to manage their own business. Thus, the change of business requires a next generation of marketing and respectively, a brand new marketing organization.

The main purpose of the paper is to open a discussion where is a need of new marketing organization as well as does it possible to change the existing marketing or to evolve it. So, the paper is based on the good practices of the world leading companies and explore the opportunities to introduce them to the Bulgarian industrial business.

The methodology approach of the paper is based on the theoretical and methodological research of the contemporary marketing literature and lessons learnt from the business.

The structure of the paper is: 1. Introduction: next steps and requirements of Industry 4.0 approach to change business inside; 2. State of art: discussion on the marketing organization and its evolution; 3. Methodology approach: introducing the steps to establish a marketing leadership in Bulgarian industrial business; 4. Empirical results: presentation of the possibilities to enforce the evolution of marketing organization; 5. Conclusions: next steps of the good marketing practices.
\end{abstract}

Key words: Industry 4.0; Marketing organization, marketing process

JEL: D20, L80, M31

\section{INTRODUCTION}

As the next generation of industry has become important for the contemporary economy a completely newer approach to marketing organization has been needed. The new industry, so called Industry 4.0, is a result not just by development of new technologies but it is a result of new entrepreneurial mindset. Basically, the Industry 4.0 is a result of Industrial policies' of the well-developed countries that have introduced innovations, entrepreneurship and human capital as the most important elements of contemporary business culture. Respectively, a brand new (innovative and entrepreneurial) mindset needs a brand new marketing approach.

But first, we need to define what Industry 4.0 is.

Industry 4.0 is used to explain the digitalization of industry that is based on new communication technologies and resp. based on Internet technologies. These

*Correspondence to: Nikolay Sterev, University of National and World Economy, Sofia, sterew@abv.bg communication technologies change the manufacturing inside as a wide spread of information, of Internet of things have arose new opportunities for the business. These $4^{\text {th }}$ industrial revolution more generally is a change of values through increasing social networking (1).

The final result is a highly innovative business (START-UPs) based on rethinking of way of doing business. The new way of doing is result of crossing lines between operational excellence and leverage of emerging technologies or leverage of shifting business models. For the making Start-ups more Smart, there is need of smart shifting between: digitalization of intelligence process; new conversions of the real physical factory; better integration between humans and machines; establishment big data mining.

The new Industry 4.0 is a factory of future based of open innovations, additive manufacturing, and smart customer management systems. The elements of such social business networking is introduction of co-workshop between real and virtual 
production systems ${ }^{1}$. But CPPSs are not just social business network it is defined as a smart factory that consist 4 elements: internet of data; internet of people; internet of service; and internet of things (2-3).

The main characteristics of Industry 4.0 that are very important to marketing organization are:

- Vertical integration of smart production systems

- Horizontal integration of global value chain networks

- Cross-disciplinary through-engineering value chain

- Acceleration through exponential technologies as artificial intelligence.

In addition, in the Industry 4.0, the internet of things accelerate the speed of combining the software of Informational technologies and operational management technologies. This could shorten the way between clients, CRM Systems and production facilities. This means a better convergence (pre-convergence) between industry and clients (4).

\section{State of Art}

The basics of the Organization are given in the social sciences a century ago as the Max Weber defines that the organization is a network to distribute the authorities (resp. commands). A modernistic approach explain the organization as a cooperative adaptive system not just made by formal administrative constructions but also by informal (social) networking (5-6).

More deeply, the organization is defined in American Heritage Dictionary of the English Language and the main elements of definition are the next ones (7):

- something that has been made into an ordered whole

- an organism that is made up of elements

- a group of persons organized cooperatively for a particular purpose.

Considering the above definition, we can explain the MARKETING ORGANIZATION as:

an order and the cooperation between individuals, resp. their market activities, which determine the independent existence of marketing function as a major business process related to the exchange of benefits between the producer and the customers using a variety of production factors.
According to the given definition three elements of the marketing organization is identified (8):

- marketing organization is a formal structure of the administrative units (resp. workplaces) that are responsible for application of marketing in the business organization. So, the marketing organization is equal to the marketing team;

- marketing organization is the order of the marketing competences (resp. individual and team tasks, responsibilities and duties) for the implementation of the marketing activities. So the marketing organization is equal to marketing structure;

- marketing organization is a cooperation work for exchanging benefits between different stakeholders. So, the marketing organization is the social market network and expressed the existence of marketing leadership.

In addition, the definition of the marketing organization is based on three main principles on which the contemporary marketing is built on:

- The company must be active on the market: This principle is an expression of the attention given to consumers as a main stakeholder. It is expression of the orientation towards action of the producer's market. By fulfilling this principle, the business does not produce "something" and waits for a solvent customer to appear but, on the contrary, actively seeks and offers its products even before it has been produced;

- Marketing function must be at least equal to the others business functions: This principle is an expression of prioritization of the business functions. Implementation of the principle allows the marketing organization to be more efficient and makes it possible to carry out marketing tasks and duties in a successful way for the business.

- Marketing organization must perform marketing integration tasks: This principle allows the marketing activities to be done not just in formal administrative unit but to be spread out in different business units. According to the principle, marketing organization has to cooperate and to integrate its task with other structural units in order to perform its main obligations.

As a result of changing understanding of definition of marketing organization Kotler (9) explain the difference between traditional and modern organization (Figure 1)

\footnotetext{
${ }^{1}$ Cyber-physical production systems (CPPSs) 


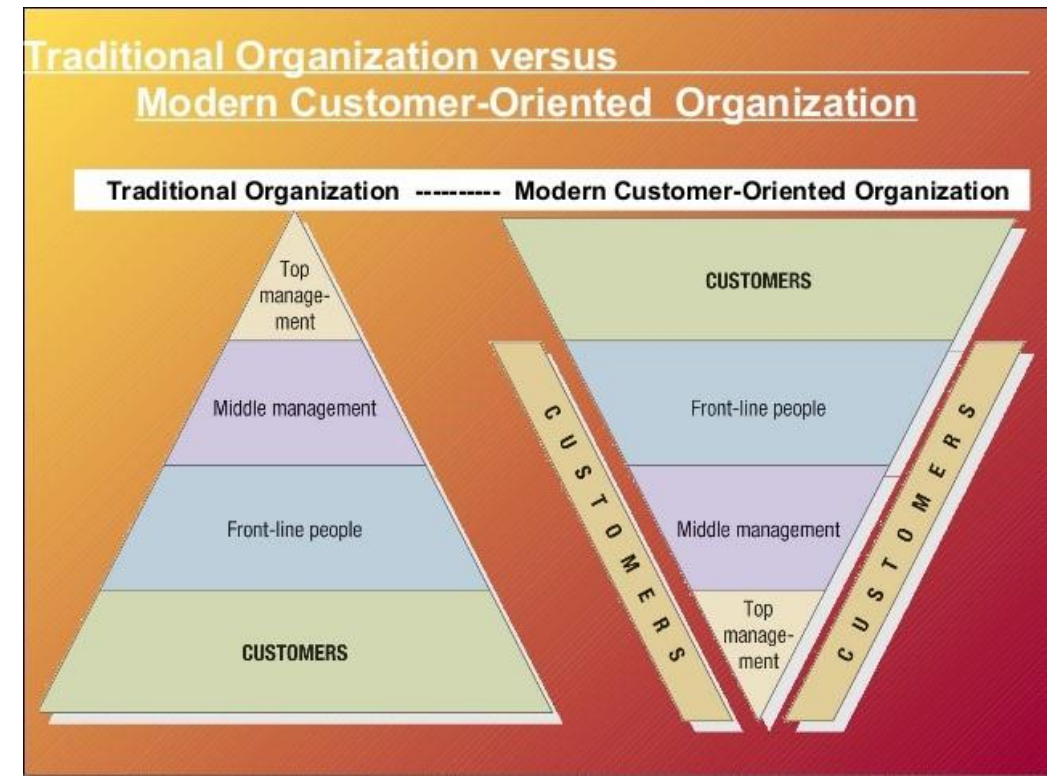

Figure 1. Approaches to marketing organization

\section{Methodology approach}

As a result of development the Industry to Industry 4.0 the marketing organization has to answer to this change. So, not just the formal administrative units have to be re-thought (see Fig.1), but also the main activities of the marketing function.

The traditional understanding of the role of marketing organization gives the marketing the responsibilities to sell the product and to communicate with clients. But fulfilling the characteristics of Industry 4.0, the smart industrial business gives the marketing organization additional responsibilities to establish a new added value chains by vertical and horizontal network integration as well as to participate in cross-disciplinary value exchange. So, the smart industry needs:

\section{Production organization}

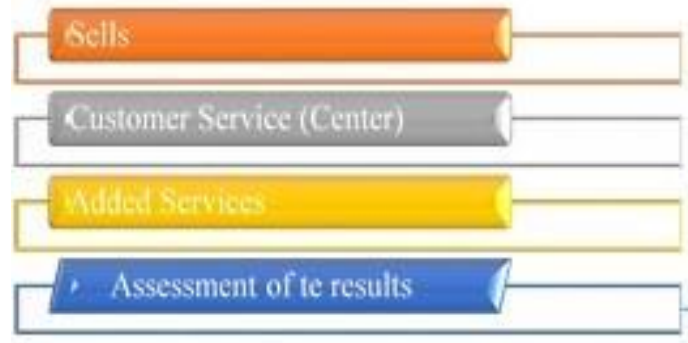

- more objective resp. machine to machine, market intelligence;

- clear product value sharing through horizontal and vertical networks;

- establishment of social business networking and enlargement of communication channels to different stakeholders;

- introduction of different software application, especially for Customer management systems and etc.

More generally, the needs of re-think the marketing organization in Smart START-Up Industry 4.0 business is a result of the "war" between production organization and marketing organization of marketing activities (Figure 2)

Figure 2. Production organization Vs. Marketing organization of marketing activities

To ensure that the marketing organization possess the ability required for marketing excellence, the people (resp. marketing units) have to fulfill the next requirements.

- Business leaders possess a strong marketing expertise;

- Marketing/sales teams in the company consist of knowledgeable, skillful and highly motivated people;

\section{Marketing organization}

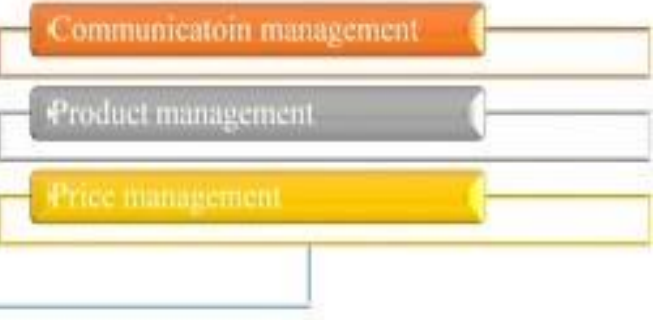

- All organization staff is well trained and highly skilled with respect to e-business instruments;

- Implemented business processes are customer/end-users application-driven;

- A business culture to achieve marketing excellence and to enforce a competitive advantage is established; 
- As a part of the business culture, a clear understanding of Market Positioning is applied.

In order to fulfill the given requirements, the main actions for the best establishment of the marketing organization needs three consecutive steps to be followed (10-11):

- First step: establishment of effective structural units of marketing that are responsible for the application of marketing in the Industry 4.0 companies;

- Second step: defining the marketing competences (resp. tasks, responsibilities and duties) for the implementation of the marketing activities in any marketing unit/position;

- Third step: establishment of effective marketing leadership.

\section{Empirical results}

The main question of the paper is whether Bulgarian Smart Industry 4.0 companies are ready to re-think their marketing organization. The research covers more than 40 enterprises and it's done by deep interviews instruments in the period 2016-2017. The main results of the research could be summarized at the next assessment table (Table 1)

Table 1. Assessment of level of marketing organizations

\begin{tabular}{|l|l|l|}
\hline 1. & $\begin{array}{l}\text { The marketing function as well-defined business function (by unit establishment) } \\
\text { exits }\end{array}$ & $75 \%$ \\
\hline 2. & The marketing organization focuses on a market defined by customers' needs & $20 \%$ \\
\hline 3. & $\begin{array}{l}\text { The marketing organization applies internet instruments on immediate customers } \\
\text { needs' specifications }\end{array}$ & $5 \%$ \\
\hline 4. & $\begin{array}{l}\text { The marketing organization is based on clear marketing unit descriptions for all } \\
\text { marketing functions }\end{array}$ & $65 \%$ \\
\hline 5. & $\begin{array}{l}\text { The people involved in marketing organization continuously upgrade their skills } \\
\text { through ongoing training in the basics of Marketing process }\end{array}$ & $10 \%$ \\
\hline 6. & $\begin{array}{l}\text { Business leaders understand the relevance and importance of marketing for the } \\
\text { success of their business }\end{array}$ & $55 \%$ \\
\hline 7. & $\begin{array}{l}\text { The ability of company to become consumer-focused is recognized by the } \\
\text { General management and it requires new roles and structure }\end{array}$ & $5 \%$ \\
\hline 8. & Marketing organization is end customer-focused instead of product-focused one & $3 \%$ \\
\hline 9. & $\begin{array}{l}\text { Different teams (organizational units) know how to manage proactively their } \\
\text { activities }\end{array}$ & $0 \%$ \\
\hline Source Own calculions
\end{tabular}

Source: Own calculations

According to the given data, most of the Industry 4.0 companies need to re-think their marketing organization. Most of them have established a formal administrative-based marketing organization but everything fail when the inbound and out-bound cooperation and integration work and network is needed.

A good instrument is organizational planning by introducing horizontal and vertical networking of the marketing organization. It is based on defining the main elements/activities of the MARKETING PROCESSES and how they interact with other processes or stakeholders. The combination of any different marketing activities gives the individual value-based marketing process that have a lot of vertical and horizontal cross-points. An example is given at Figure 3.

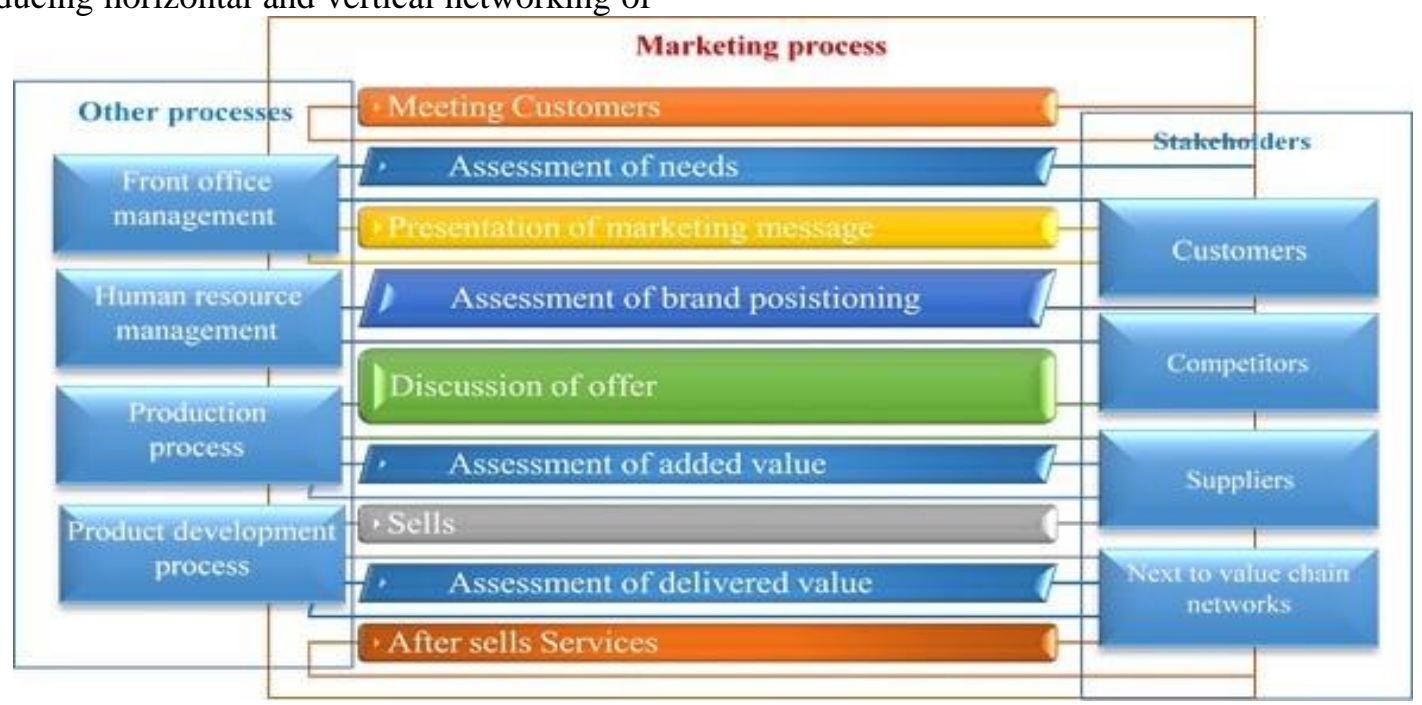

Figure 3. Horizontal and vertical networking in marketing organization 


\section{CONCLUSIONS}

The problem of organizing marketing is undoubtedly important to Industry 4.0 business. And, it is important not only because of official/artificial structure the marketing units in the organizational management scheme, but also because marketing organization need to be defined accurate and correct guidelines for the processes of production and sales of services, as well as their decomposition into individual marketing activities

The marketing excellence examples show an evolving of marketing organization especially in Industry 4.0 companies as a number of leading global companies reorganize and establish the full marketing leadership. At this level of marketing excellence they introduce not just key indicators in different processes (for example: production, delivery management etc.) to manage the marketing effectiveness but they establish internet application for immediate customers and competitors market response.

Notwithstanding the advantages of the given approach, the re-think about marketing organization is related to the best definition of marketing process and connection with horizontal and vertical cross-lines with other business processes and/or stakeholders. The cooperation as well as the interactive instruments for cooperation could make the contemporary industry companies to be SMART ones.

\section{REFERENCES}

1. Blagoev, D., Kopeva, D., Sterev, N., Jordanova, Z., 2015, START-UP FOR SUSTAINABLE GROWTH IN BULGARIA, Trakia Journal of Sciences, Volume 13, Issue 1, pp. 318-322, http://www.uni-

sz.bg/tsj/Vol.\%2013,\%202015,\%20Suppl.

$\% 201, \% 20$ Series\%20Social\%20Sciences/S

F/SF/Predpriem.\%20i\%20biznes/D.Blagoe v.pdf

2. Schlaepfer R. and M.Koch, Industry 4.0: Challenges and solutions for the digital transformation and use of exponential technologies, Deloitte AG Report 2015,
Zurich,

https://www2.deloitte.com/content/dam/Del oitte/ch/Documents/manufacturing/ch-enmanufacturing-industry-4-0-24102014.pdf

3. Bloem J. at al., 2014, The fourth industrial revolution: things of tighten the link between IT and OT, Sogeti VINT, 2014, https://www.fr.sogeti.com/globalassets/glob al/downloads/reports/vint-research-3-thefourth-industrial-revolution

4. Smit J., S.Kruetzer, C.Moeller, M.Carlberg, 2016, Industry 4.0, Policy Department: A Economic and Scientific policy, ITREE Committee, European Parliament, http://www.europarl.europa.eu/RegData/etu des/STUD/2016/570007/IPOL_STU(2016) 570007_EN.pdf

5. Bittner, Egon. 1965. The concept of organization. Social Research 32(3): 239255 ,

http://edoc.zhbluzern.ch/oaj/es/ethnographi c_studies_13_17.pdf

6. Selznick, Philip, 1948, Foundations of the Theory of Organization, American Sociological Review, 13 (1948), pp. 25-35.

7. McLean, Gary N., 2005, Organization Development Principles, Processes, Performance, Berrett-Koehler Publishers, https://www.google.bg/?gws_rd=ssl\#q=org anisation+definition+pdf\&spf $=1499262306$ 045

8. Sterev, N., D.Blagoev, I.Georgiev, 2012, Enterprise economics, IK-UNSS, Sofia, 2012

9. Kotler, P., 2014, "Principles of Marketing" 15th Edition

10.Shterev N. and D.Blagoev, 2007, Characteristics of Managerial Training in Marketing by the Competencies Methods, Economic Alternatives Journal, 1EN/2007, http://alternativi.unwe.bg/alternativi/indexen.php?nid=18\&hid=433

11.Sterev, N., 2015, ANALYSIS OF LEADERSHIP'S PRACTICES OF INDUSTRIAL ENTITIES, Trakia Journal of Sciences, Volume 13, Issue 1, pp. 378386, http://www.unisz.bg/tsj/Vol.\%2013,\%202015,\%20Suppl. $\% 201, \% 20$ Series\%20Social\%20Sciences/S F/SF/Predpriem.\%20i\%20biznes/N.Sterev.p $\mathrm{df}$ 